\title{
A systematic review of transmission dynamic studies of methicillin-resistant Staphylococcus aureus in non-hospital residential facilities
}

Kin On Kwok ${ }^{1,2,3^{*}}$, Jonathan M. Read ${ }^{4,5}$, Arthur Tang ${ }^{6}$, Hong Chen ${ }^{7}$, Steven Riley ${ }^{8^{*}}$ and Kai Man Kam ${ }^{1,2}$

\begin{abstract}
Background: Non-hospital residential facilities are important reservoirs for MRSA transmission. However, conclusions and public health implications drawn from the many mathematical models depicting nosocomial MRSA transmission may not be applicable to these settings. Therefore, we reviewed the MRSA transmission dynamics studies in defined non-hospital residential facilities to: (1) provide an overview of basic epidemiology which has been addressed; (2) identify future research direction; and (3) improve future model implementation.
\end{abstract}

Methods: A review was conducted by searching related keywords in PUBMED without time restriction as well as internet searches via Google search engine. We included only articles describing the epidemiological transmission pathways of MRSA/community-associated MRSA within and between defined non-hospital residential settings.

Results: Among the 10 included articles, nursing homes (NHs) and correctional facilities (CFs) were two settings considered most frequently. Importation of colonized residents was a plausible reason for MRSA outbreaks in NHs, where MRSA was endemic without strict infection control interventions. The importance of NHs over hospitals in increasing nosocomial MRSA prevalence was highlighted. Suggested interventions in NHs included: appropriate staffing level, screening and decolonizing, and hand hygiene. On the other hand, the small population amongst inmates in CFs has no effect on MRSA community transmission. Included models ranged from system-level compartmental models to agent-based models. There was no consensus over the course of disease progression in these models, which were mainly featured with $\mathrm{NH}$ residents /CF inmates/ hospital patients as transmission pathways. Some parameters used by these models were outdated or unfit.

Conclusions: Importance of $\mathrm{NHs}$ has been highlighted from these current studies addressing scattered aspects of MRSA epidemiology. However, the wide variety of non-hospital residential settings suggest that more work is needed before robust conclusions can be drawn. Learning from existing work for hospitals, we identified critical future research direction in this area from infection control, ecological and economic perspectives. From current model deficiencies, we suggest more transmission pathways be specified to depict MRSA transmission, and further empirical studies be stressed to support evidence-based mathematical models of MRSA in non-hospital facilities. Future models should be ready to cope with the aging population structure.

Keywords: Methicillin-resistant Staphylococcus aureus, MRSA, Transmission models, Non-hospital, Residential

\footnotetext{
* Correspondence: kkokwok@cuhk.edu.hk; s.riley@imperial.ac.uk

${ }^{1}$ The Jockey Club School of Public Health and Primary Care, The Chinese

University of Hong Kong, Shatin, Hong Kong, Special Administrative Region

of China

${ }^{8}$ MRC Centre for Outbreak Analysis and Modelling, Department for Infectious

Disease Epidemiology, Imperial College London, London, UK

Full list of author information is available at the end of the article
} 


\section{Background}

Methicillin-resistant Staphylococcus aureus (MRSA) often induces infections that are difficult to treat because of its ability to survive most antibiotics. The World Health Organization has recently listed MRSA as one of the priority pathogens posing threat to human health [1]. MRSA is endemic in Hong Kong [2] with occasional outbreaks in hospitals, resulting in bacteremia, pneumonia and surgical site infections. Empirical studies have shown that non-hospital residential facilities are important reservoirs for MRSA transmission. Facilities with individuals residing for a substantial period, such as long term care facilities (LTCFs) and correctional facilities (CFs), are considered as at particularly high risk. Some studies reported that the MRSA colonization prevalence rate can be as high as $52 \%$ in nursing homes $(\mathrm{NHs})$ in the United States (US) [3-5], significantly higher than that of $1.5 \%$ in the general population [6]. The MRSA acquisition rate was reported to be higher among residents in LTCFs than their stays in hospitals [7]. MRSA was also shown to be more prevalent in CFs than in the general community [8-11].

Hospitals and LTCFs are residential settings connected by the transfer of residents or patients [12, 13]. Transmission and epidemiological characteristics of MRSA in LTCFs may be different from those in hospitals, and may contribute extensively to community level transmission. The average length of stay (LOS) is longer for residents in NHs [14] and inmates in CFs [15] compared with patients in hospitals [16]. In fact, residents in NHs were shown to carry MRSA for a considerably long period of time: asymptomatic colonization could last more than 3 years $[17,18]$. Several factors that contributed to the transmission mechanism characteristics of MRSA in non-hospital residential facilities being different from those in hospitals, including: (a) different interpersonal contact pattern; (b) different daily ward routines; (c) different health conditions of individuals in the facilities; and (d) facility-specific environmental factors.

Dynamic studies have been developed to study MRSA transmission within non-hospital residential settings. Models that explicitly represented how the risk of infection was related to the current number of infectious people [19] were useful for studying transmission dynamics, evaluating different infection control interventions, evaluating burden of infection as well as facilitating further understanding of LTCF epidemiology. Numerous mathematical models have been employed to depict MRSA transmission in hospital settings [20, 21], but the conclusions and public health implications drawn from these studies may not be applicable to non-hospital settings. In light of this, we conducted a systematic review of mathematical models for the MRSA transmission in non-hospital residential facilities. The aims of this review are to provide an overview of epidemiological understanding of MRSA transmission in non-hospital settings gained through mathematical modeling, to identify future research direction in this area and to improve future model implementation by addressing current models' deficiencies.

\section{Methods}

Non-hospital residential facilities were defined as nonhospital settings where individuals resided for a substantial period of time. Such facilities included CFs and LTCFs. Two types of CFs were jails and prisons. Jails were facilities holding individuals serving a short period (usually shorter than one year). Prisons were facilities that confine convicted individuals for a longer period. LTCFs were facilities that provided care to clients with medical services or daily needs over an extended period, including $\mathrm{NHs}$ and assisted living facilities (ALFs). NHs were mainly for elderly with medical needs. ALFs were for individuals from different ages and vulnerable groups who lived dependently, including children and people with long-term disability.

To identify studies for this review, an initial search using the PUBMED database in the field "Title/Abstract" was conducted using the following search terms:

1) MRSA OR "Methicillin-resistant Staphylococcus aureus" OR "Methicillin resistant Staphylococcus aureus" AND

2) dynamics OR agent-based OR "agent based" OR individual-based OR "individual based" OR mathematical OR Bayesian OR compartmental OR deterministic OR stochastic AND

3) "children care" OR "child care" OR jail OR prison OR custody OR correctional OR elderly OR nursing OR long-term care OR "long term care" OR "care home" OR boarding OR residential OR nonhospital OR "non hospital"

The search was further expanded by internet searches using the keywords "MRSA", "transmission", "dynamics", "modelling" and "correctional" in Google search engine on 26 May 2017. Results were screened up to the fifth pages returned from the internet search.

Only articles depicting epidemiological transmission pathways of MRSA/community-associated MRSA within and between defined non-hospital residential settings were included in this review. Population-level studies were excluded. Included articles were summarized in terms of: study aims, countries for model inference, model types and forecast period, disease progression and transmission pathways characterized by the model, and technical model execution details (model assumptions, parameter values, and ways of parameterization). 
Two authors (KOK, SR) screened the titles and abstracts of articles obtained from the initial search. To finalize articles included in this study, two authors (KOK, SR) read the full-text of the shortlisted publications and excluded articles that did not fit into the context for this review.

\section{Results}

The search was performed in the PUBMED database on 23rd April 2017. Ten articles were identified from the PUBMED database and by internet searches (Fig. 1). Three studies focused on MRSA transmission dynamics within NHs [22-24], three focused on that associated with CFs [25-27], and four focused on that between facilities [28-31]. Seven aspects of basic epidemiology of MRSA in non-hospital residential settings and model frameworks of included studies were summarized.

\section{Role of health-care workers (HCWs) and residents in transmission mechanisms within $\mathrm{NHs}$}

Only one study represented HCWs and residents explicitly [22]. Potential outbreaks in NHs were considered more likely due to an imported MRSA colonized resident than due to contaminated HCWs [22]. The two studies conducted by Batina et al. did not consider HCWs in the transmission dynamics [23, 24]; only residents were considered. In the two models, residents were further classified based on their antibiotics use in the past three months. Residents with antibiotics exposure were more likely to acquire MRSA [24], increasing strain-specific MRSA prevalence [23]. None of these three studies considered HCWs as MRSA long-term carriers.

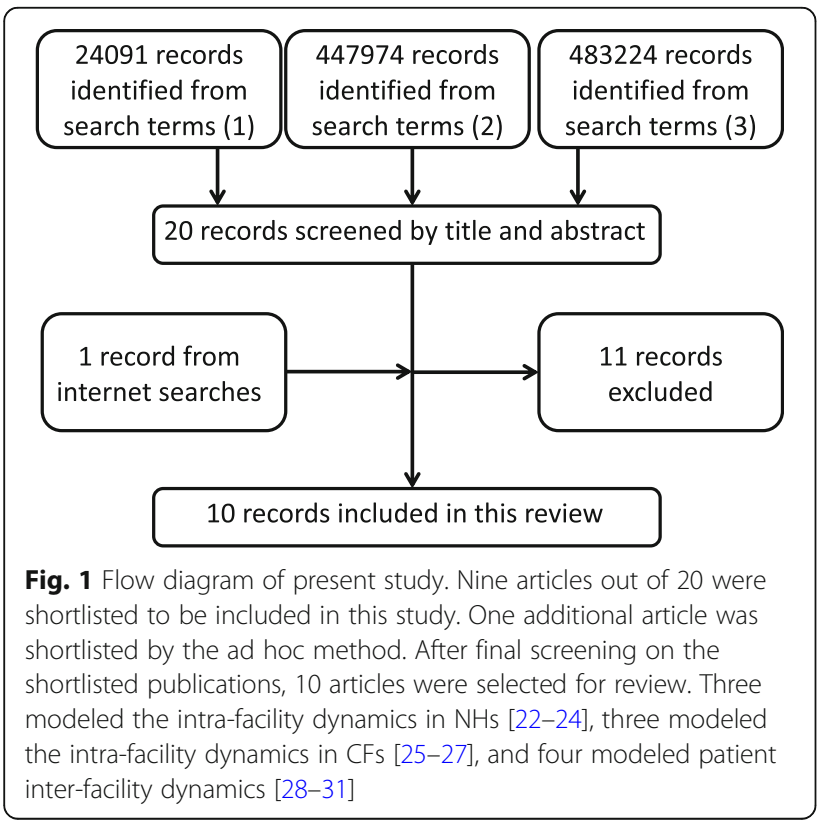

\section{Intervention strategies to control MRSA transmission} within NHs

Appropriate staffing level for better infection control was suggested [22]. Given the presumed homogeneous mixing, increasing staff-to-residents ratio lowered the average number of contacts between HCWs and residents, resulting in a decrease of MRSA prevalence [22]. Screening and decolonizing colonized residents at admission were suggested by Chamchod et al. [22] and Batina et al. [23]. Chamchod et al. showed that MRSA would persist in $\mathrm{NHs}$ without screening and decolonization strategies [22]. Batina et al. highlighted the same strategies could theoretically eradicate MRSA in NHs [23]; and in practice these strategies could at least reduce the prevalence. Hand hygiene practices for residents and HCWs was suggested by Chamchod et al. [22].

\section{Persistence of MRSA within NHs}

Long-term MRSA dynamics were used to investigate the possibility and magnitude of MRSA endemicity [22-24]. MRSA was endemic in NHs if no effective infection control intervention was implemented. However, MRSA could possibly be eradicated by strict screening and decolonization of colonized individuals at admission [22, 23]. Batina et al. concluded that an outbreak was unlikely to occur except in extraordinary conditions such as multifold increase in MRSA acquisition rate [23].

\section{Outbreak potential within CFs}

Kajita et al. suggested that outbreak potential was small unless inmates were interned for at least 2 to 2.5 months [25]. Beauparlant et al. suggested that the increased inflow and outflow from high recidivism might lead to a sustained prevalence within CFs when re-offending rates were high [26].

\section{Impact of CF-community MRSA dynamics}

Kajita et al. reported that within-jail MRSA transmission was sufficient to sustain continual outbreaks if there is a continuous inflow of colonized and infected individuals from the community [25]. Beauparlant et al. also suggested that outbreaks in jail were driven by community dynamics but CFs would not significantly affect community MRSA dynamics [26]. Despite findings that hospitals and prisons released a similar number of newly colonized individuals into community at an average rate [27], the small population size of prison made the impact of MRSA dynamics in community negligible [26].

\section{Impact of LTCF-hospital MRSA dynamics}

Barnes et al. suggested that patient movement between hospitals and LTCFs contributed significantly to MRSA prevalence in LTCFs [28]. The endemic prevalence within 
LTCFs was shown to be positively associated with the MRSA prevalence of hospitals with which patients were shared. Patient transfers from hospitals were found to result in sustained increased in MRSA prevalence in LTCFs, particularly those with small population size and low residents' turnover rates. Lesosky et al. studied MRSA transmission dynamics between NHs and hospitals in one metropolitan area [31]. They suggested the importance of NHs over hospitals in affecting the overall nosocomial MRSA prevalence when endemic prevalence was in almost all institutions. The increased transmission rate in a single NH caused a substantially higher percentage change to overall nosocomial MRSA prevalence than that caused by increased transmission rate in a single hospital when MRSA was endemic in all health-care settings. Changes in patient transfer rates or patterns among mainstream facilities did not significantly change the hospital MRSA prevalence [31]. Lee et al. stated that an MRSA outbreak in the largest $\mathrm{NH}$ increased the average MRSA prevalence in multiple hospitals with direct and indirect patient transfer for 6 months [29]. NHs should be considered as an important setting to implement hospital infection control strategy [29].

\section{Intervention strategies to control inter-facility MRSA transmission}

Following the findings by Lesosky et al. [31], Lee et al. suggested that contact precaution use on known colonization carriers by reducing their contact rates in NHs could substantially reduce MRSA transmission in both NHs and hospitals [30].

\section{Modelling frameworks}

Most reviewed studies depicted disease dynamics on a system level by compartmental models and were solved deterministically [22, 23, 25, 26]; three included stochastic solution [22, 23, 25], one used a Markov model [24] and one presented findings based on analytical results [27]. Some studies modeled disease dynamics with individual-level agent-based models $[29,30]$ and Monte Carlo simulation model [31], in which an individual was regarded as an agent with their own inter-facility movements and infection states. Hybrid models combining agent-based model (facilities are regarded as agents) and compartmental model (within-facility) were also used to describe the transmission dynamics on both system level and local level [28]. Table 1 summarizes key aspects of models featuring MRSA transmission dynamics in different settings, including model features and transmission pathways.

Different representations of disease progression were defined (Table 1). Three main transition states in MRSA were generally considered: uncolonized (U), colonized (C), and infected (I). Some studies further divided the colonized state into persistently-colonized (P) and transiently-colonized (T). The model by Chamchod et al. only considered U-C in their framework [22]; the model by Kajita et al. considered U-C-I in their framework [25]; and the model by Barnes et al. considered U-P-T in their framework [28]. The relative importance in the transmission contributed by infected and colonized agents was addressed in U-C-I framework.

To depict transmission dynamics, endogenous and exogenous transmission pathways were explicitly stated in intra-facility and inter-facility transmission models. For intra-facility transmission models, endogenous pathways mainly described pathways that resulted in residents' infection in NHs [22, 23] or CFs [25, 26]. HCWs were considered as transient host in one study only [22], and were defined as vectors to transmit MRSA via contaminated hands with "contaminating" time being less than an hour. At present, no reviewed article in CFs included staff in the transmission pathways. Exogenous pathways focused on the imported colonized residents. For interfacility transmission models, the transmission pathways focused on patient transfers between the same type (hospital-hospital movements) or different types (LTCF-hospital movement) of facilities (Table 1).

Some common assumptions were made across all reviewed articles. One common assumption made was homogeneous contact mixing within the facility [22, 23, 25, 26, 28-31]. Another common assumption was fixed patient transfer rates in either hospitals or LTCFs, reflecting these movements were performed on a regular basis [22, 23, 28-31].

\section{Discussion}

The scientific contributions to MRSA epidemiology of the 10 mathematical models were reviewed and summarized. To exhaust literatures specific to this research area, the search was based on both PUBMED and Google search engine. NHs provided ideal reservoirs for potential MRSA outbreaks in hospitals [22, 28]. It is further highlighted the role of NHs in the increasing nosocomial MRSA prevalence and the need for appropriate interventions in NHs [29-31], including contact precaution and intervention for residents with different colonization state (transiently colonized vs persistently colonized). Community colonization in NHs was found to have a strong effect on nosocomial colonization rates when MRSA was endemic in the health care system [31]. The relatively small population in prisons compared to the general public was found to be insignificant to MRSA community transmission [26, 27]. There was no consensus over the course of disease progression among reviewed models, which were mainly featured with $\mathrm{NH}$ residents /CF inmates/ hospital patients as transmission pathways and based on unrealistic 
Kwok et al. BMC Infectious Diseases (2018) 18:188

Page 5 of 13

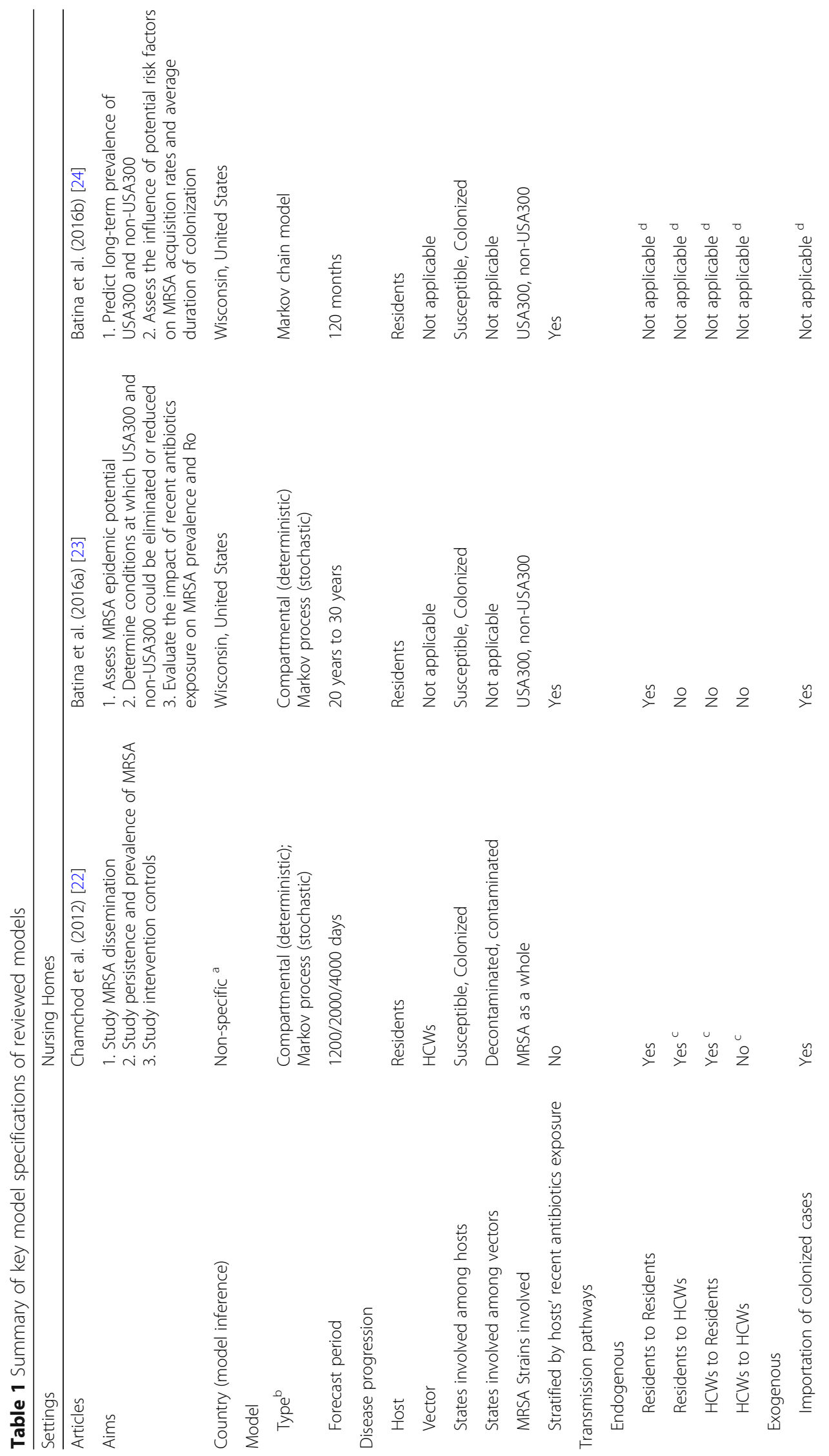




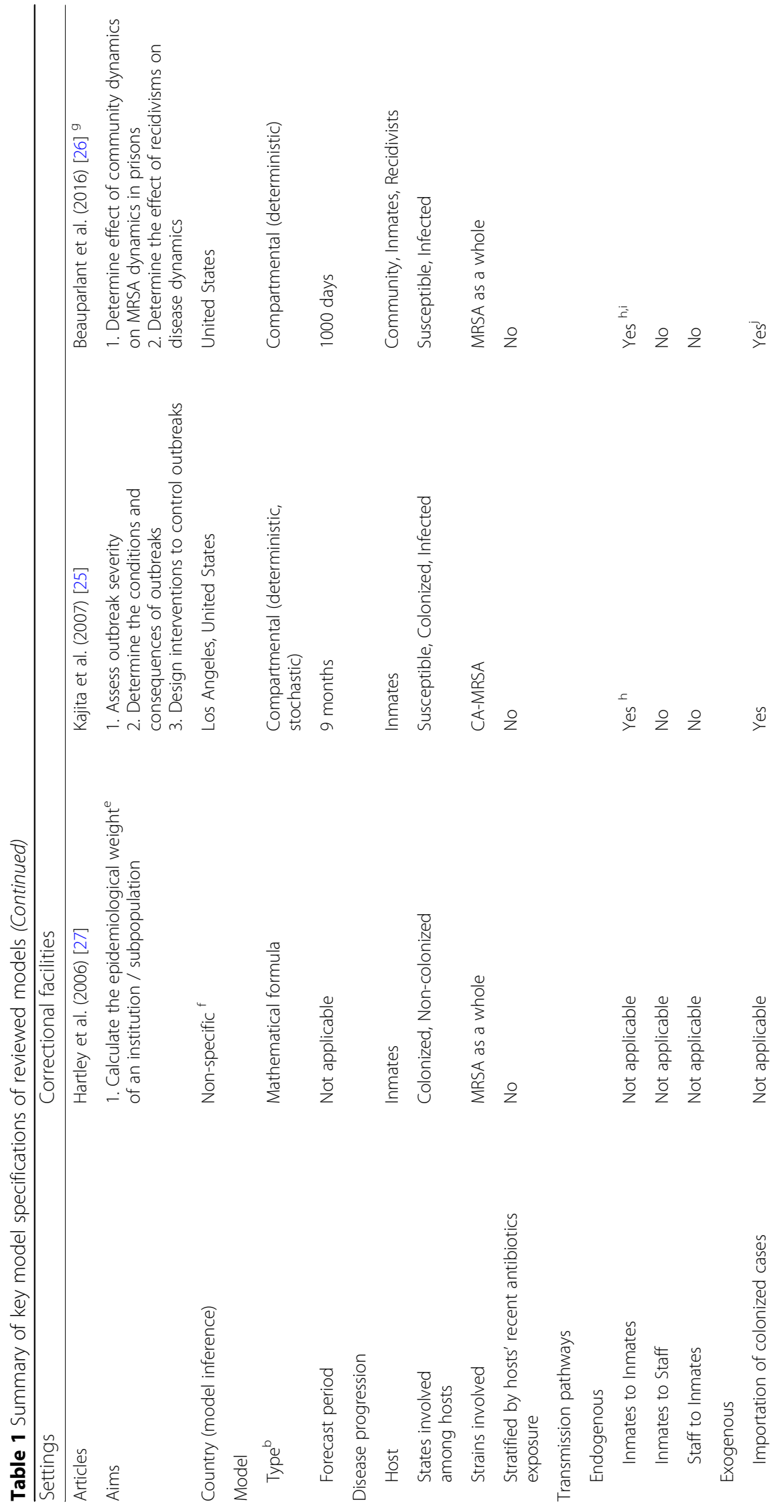


Kwok et al. BMC Infectious Diseases (2018) 18:188

Page 7 of 13

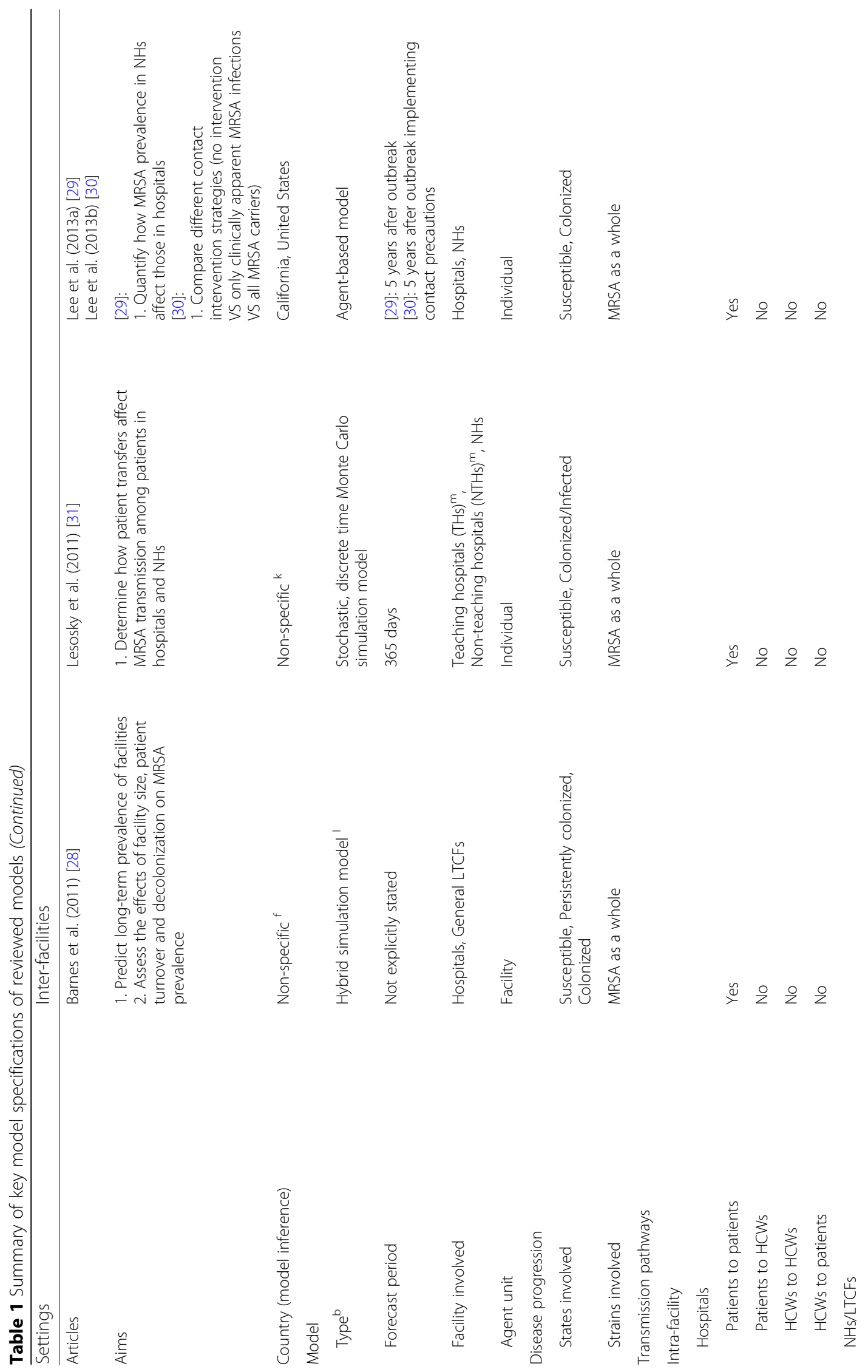




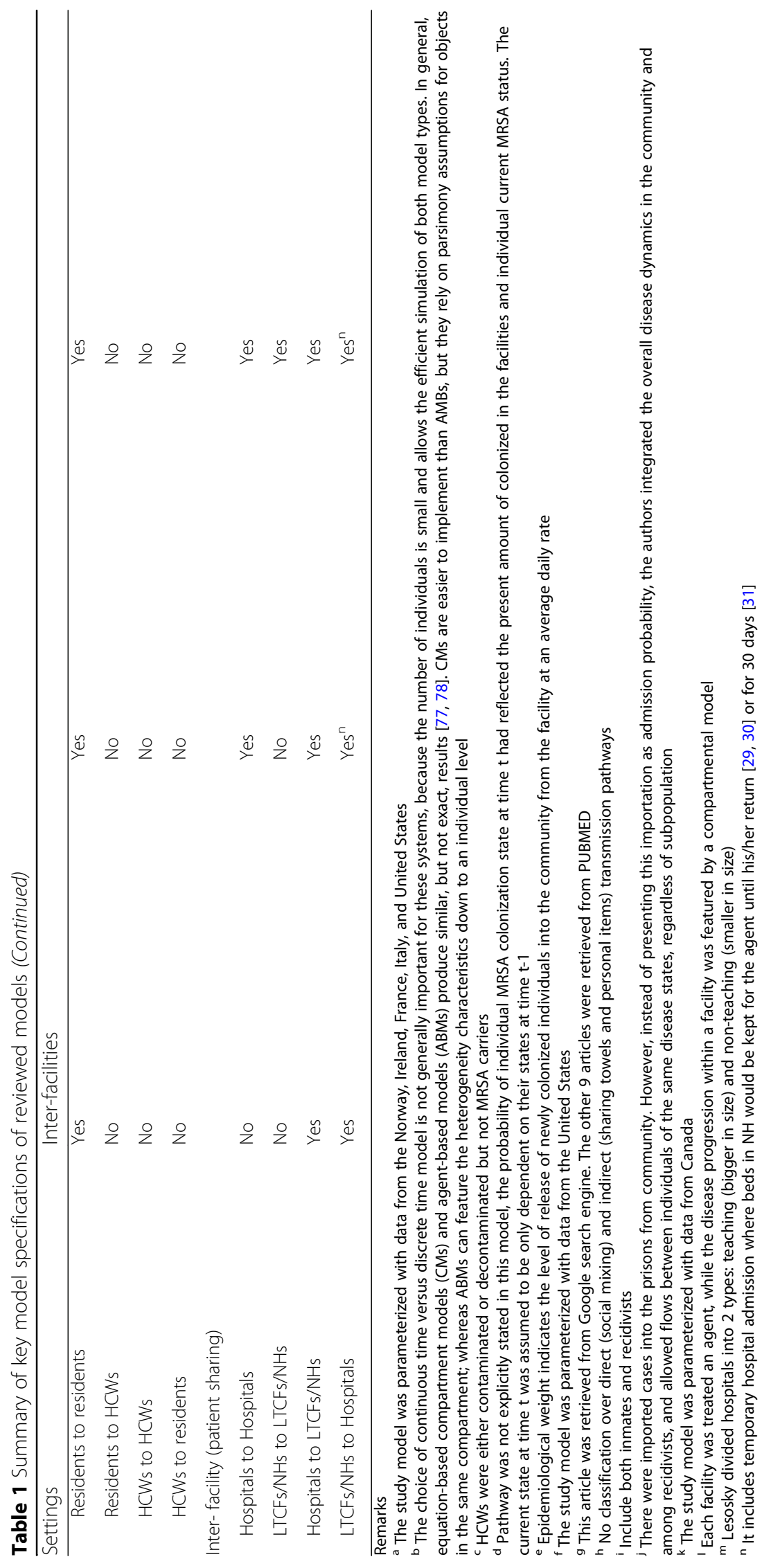


assumptions. Some parameters used by these models were outdated or unfitted.

The reviewed models provided a starting point for future model development for intra-facility and interfacility MRSA transmission. Moreover, infection control implications, transmission pathways, improvements for future work and future research direction can be identified from these models.

\section{Implication of infection control}

MRSA epidemiology in hospitals is different from that in non-hospital residential settings. Therefore, traditional infection control measures for MRSA used in the hospitals are unlikely to be ineffective or inadaptable for LTCFs and CFs. For example, the minimization of stay is a common intervention in hospital settings but is inappropriate for LTCFs and CFs. Future strategies for MRSA prevention should include admission screening in LTCFs and discharge screening in CFs and hospitals, as well as longitudinal screening for residents. Screening at admission is supported by findings that a significant factor associated with MRSA epidemic in NHs was the introduction of MRSA colonized residents [22]. Frequent movement of $\mathrm{NH}$ residents from hospitals was also found to contribute to MRSA prevalence of small population LTCFs with small facility size and low turnover rate [28]. This practice is particularly important for residents with recent antibiotics exposure, as recent antibiotics exposure significantly increased MRSA acquisition rate and strain-specific MRSA prevalence [23, 24]. In addition, the similar rate of releasing colonized individuals from CFs and hospitals to the community [27] and the impact of recidivism on MRSA incidence in CFs [26] highlight the importance of discharge screening in all these facilities. Regular screening on residents during their stay should also be a part of infection control policy, as suggested by hospital study results that patients with negative screening results at admission can subsequently be colonized [32-34]. Consideration should also be made on how to prioritize different intervention strategies imposed on individuals with different colonization states [30]. It is noted that screening results are usually available 2-3 days after the test. Before the screening results are available, it is pertinent to recognize the use of isolation measures and their availability.

Other control measures include contact precautions and hand hygiene policy. Some hospital infection control guidelines [35] recommend contact precautions, including equipping staff with gowns and gloves. Preventing infected residents from entering cohorted rooms and equipping with protective clothing should be recommended for reduction of MRSA transmission in NHs [30]. Implementation of hand hygiene policy could have immense influence on the transfer rates of skin organism
[36]. Inanimate items should be considered when considering suitable intervention strategies [37-39].

Difficulty in executing infection control policies varies. Screening and contact precaution require decisions at national, or at least institutional, level; while hand hygiene is more of facility or personal level and can be easily achieved through promotion. Therefore, implementing hand hygiene promotion while awaiting decisions for other policies shall be the optimal infection control schema.

\section{Transmission mechanisms of MRSA}

Of the 10 reviewed studies, 9 of them considered residents/inmates as the only transmission pathway. Only one considered non-residents/non-inmates as a transmission pathway [22]. Prior study estimated MRSA carriage prevalence of $4.6 \%$ in 127 investigations among HCWs, and suggested that both transiently and persistently colonised HCWs were associated with several MRSA outbreaks involving few clusters [40]. Another study reported a colonization rate of $6.9 \%$ among nursing staff in non-outbreak situations [41]. None of the three reviewed models for CFs considered staff as a transmission pathway. The role of staff would need to be considered in future models as the number of staff present in LTCFs and CFs is likely to increase MRSA colonization or infection rates among residents.

Environmental contaminated objects, facility visitors and antibiotics resistance development were not considered in the 10 reviewed studies. Environmental contaminated objects were reported as a source of MRSA transmission [42]. Environmental intervention strategies have also been supported by modelling studies in hospital settings [43-46]. Environmental pathway had been shown to be important for crowded settings with limited hygiene resources, such as CFs and LTCFs [47-49]. Visitors' role in MRSA transmission in hospital settings had been suggested as being significant pathways in nonhospital settings [50]. Besides, appearance of MRSA in the community may also increase the risk of MRSA carriage transfer from visitors to individuals in LTCFs or CFs [51]. Patients' antibiotics exposure was found to be an important pathway by modelling studies in hospital settings [52] and by current reviewed studies [23, 24]. Future models for non-hospital facilities need to take these three pathways into consideration to increase their results applicability reflecting practical situations in the facilities.

The relative importance of different transmission modes was not considered in all 10 reviewed models. Chamchod et al. considered transmission via hands of HCWs [22]. However, it was also reported that: HCWs were contaminated with MRSA on their bodies [53]; An increase in MRSA-containing particles was shown in the air during and after bedmaking [54] or when the carriers 
suffered from upper respiratory tract infection [55]. Therefore, although transmission via contact is still considered as the main mode of transmission, the potential for other modes should be not eliminated.

Another element to be considered when building MRSA transmission models for non-hospital residential facilities is facility-specific characteristics, including: (a) LOS; (b) setting-specific risk factors; and (c) geographical and cultural differences. Previous studies found that LOS is a significant mediator of hospital-acquired MRSA [56]. This factor is not considered in the 10 reviewed models. Young age is a setting-specific risk factor for CFs [57]. This setting-specific risk factor can be utilized to develop age-structured model [58] for studying agespecific transmission patterns in CFs. Geographical and cultural differences in each type of facility may also impact transmission patterns. Factors such as climates, social practices and cultural behaviors may possibly act as mediators in transmission dynamics.

The ecological dynamics of MRSA strains were not well addressed in the reviewed models. Despite the hypervirulence possessed by strains being to the USA300 clone compared to other MRSA strains [59, 60], 8 of 10 models in this review did not differentiate the clones of MRSA under investigation. Only two recent models considered the transition of infections between USA300 and non-USA300 clones allowed an explicit niche of co-existence for these clones [23, 24]. However, the degree of competition for colonization of susceptible hosts or constructive interference of strains was not quantified [61].

\section{Model deficiencies}

Some technical modelling execution deficiencies were listed in Additional file 1, Additional file 2 and Additional file 3. Empirical data used for parameterizing models were not updated. Empirical data for CFs is inadequate: there is no data available to parametrize the average decolonization duration of inmates, the proportion of colonized individuals progressing to infection and the average daily number of contacts in a CF [25]. In the inter-facility model by Lesosky et al. [31], the hospital colonization status parameters used were from the proportion of community MRSA positivity in 1998 and 2001-2004. Some of the reviewed studies did not state the years of data source and the parameter estimation procedures in their mathematical models (Additional file 1, Additional file 2 and Additional file 3).

Homogeneous social contact mixing was assumed in 8 of the 10 reviewed models [22, 23, 25, 26, 28-31]. This assumption would be unrealistic in many situations. Contact patterns have been found to be assortative with age in the general population [62]. The contact pattern within age groups was shown to be a key driver of age- specific infection rates [63]. Patterns of social contact mixing are greatly disparate across individuals in healthcare settings [64, 65]. Various health conditions of $\mathrm{NH}$ residents may cause their social contact mixing to be significantly more heterogeneous than the general population. It has also been found that CF inmates often intended to have low number of contact [25], but social contact among CF inmates was also expected to be heterogeneous. These factors should be incorporated into future models.

Almost all existing models are built explicitly for or informed by data from the US (Table 1). The existence of MRSA in non-hospital residential settings outside the US $[66,67]$ and the existence of geographic discrepancy in MRSA epidemiology [66] suggest there is a need for future modelling in other regions, such as Asia and Europe.

\section{Directions forward}

Based on the transmission mechanisms of MRSA and examination of current model deficiencies, a list of recommendations for future mathematical transmission model development was composed (Additional file 4).

An evaluation of ongoing approaches by the latest MRSA modelling researches on hospitals shed light on future directions of MRSA modelling researches for non-hospital residential facilities in three perspectives: 1 ) infection control [28, 32, 68-73]; 2) ecology [74]; and 3) economy [27] (Additional file 5).

Future models should be ready to face the projected challenges from changes in population structure. The expected doubling of people over 60 by 2050 [75] put escalating demand for LTCFs. Decreasing average resident living area in the facilities will affect MRSA prevalence in LTCFs. In addition, the wide varieties of LTCFs, such as child day care center [76], suggest more modeling work is needed before robust conclusions can be drawn.

\section{Conclusions}

Modelling studies on this important topic are at their initial phase of development and we identified critical opportunities for future work although many mathematical frameworks [77, 78] have been developed in previous studies. Importance of $\mathrm{NHs}$ has been highlighted from these current few studies addressing scattered aspects of MRSA epidemiology. However, the wide varieties of non-hospital residential settings suggest more work is needed before robust conclusions can be drawn. Learning from existing work for hospitals, we identified important future research direction in this area from infection control, ecological and economic perspectives. From current model deficiencies, we suggest more transmission pathways be specified to depict MRSA transmission, and further empirical studies should be stressed to support evidence-based mathematical models of MRSA in non-hospital facilities. Future 
models should also be ready to cope with the aging population structure.

\section{Additional files}

Additional file 1: Technical model execution details for models in NHs. (DOCX $25 \mathrm{~kb}$ )

Additional file 2: Technical model execution details for models in CFs. (DOCX $26 \mathrm{~kb}$ )

Additional file 3: Technical model execution details for inter-facility models. (DOCX $36 \mathrm{~kb}$ )

Additional file 4: Recommendations for the future mathematical transmission model development based on A) Transmission mechanisms of MRSA; and B) Current model deficiencies. (DOCX 25 kb)

Additional file 5: Future directions of MRSA modelling researches for non-hospital residential facilities from 3 perspectives. (DOCX $20 \mathrm{~kb}$ )

\section{Abbreviations}

ALFs: Assisted living facilities; C: Colonized; CFs: Correctional facilities; HCWs: Health-care workers; I: Infected; LOS: Length of stay; LTCFs: Long-term care facilities; MRSA: Methicillin-resistant Staphylococcus aureus; NHs: Nursing homes; P: Persistently-colonized; S. aureus: Staphylococcus aureus;

T: Transiently-colonized; U: Uncolonized

\section{Acknowledgements}

We would like to acknowledge Prof. SS Lee, Professor at the Chinese University of Hong Kong, for his comment of this manuscript. KOK acknowledges Li Ka Shing Institute of Health Sciences for providing technical support in the research.

\section{Funding}

This study was funded by the Health and Medical Research Fund of the Health, Welfare and Food Bureau of the Hong Kong SAR Government (grant nos. CU-17-C18). SR acknowledges support from Wellcome Trust (200861/Z/16/Z); Medical Research Council, UK (Project MR/J008761/1); National Institute for Health Research (UK, for Health Protection Research Unit funding); the National Institute of General Medical Sciences (MIDAS U01 GM110721-01). JMR acknowledges support from the ESRC (ES/ K004255/1, RES-355-25-0019)

\section{Availability of data and materials}

Not applicable.

\section{Authors' contributions}

KOK and KKM designed the study. KOK and SR performed the search and data extraction. KOK, JMR, AT, SR analyzed the data. KOK, AT, SR and KKM wrote the manuscript. JMR and $\mathrm{CH}$ edited the draft. All authors read and approved the final manuscript.

\section{Ethics approval and consent to participate}

Not applicable.

\section{Consent for publication}

Not applicable.

\section{Competing interests}

The authors declare that they have no competing interests.

\section{Publisher's Note}

Springer Nature remains neutral with regard to jurisdictional claims in published maps and institutional affiliations.

\section{Author details}

${ }^{1}$ The Jockey Club School of Public Health and Primary Care, The Chinese University of Hong Kong, Shatin, Hong Kong, Special Administrative Region of China. ${ }^{2}$ Stanley Ho Centre for Emerging Infectious Diseases, The Chinese University of Hong Kong, Shatin, Hong Kong, Special Administrative Region of China. ${ }^{3}$ Shenzhen Research Institute of the Chinese University of Hong Kong, Shenzhen, China. ${ }^{4}$ Centre for Health Informatics Computing and Statistics, Lancaster Medical School, Faculty of Health and Medicine, Lancaster University, Lancaster, UK. ${ }^{5}$ Institute of Infection and Global Health, The Farr Institute@HeRC, University of Liverpool, Liverpool, UK. ${ }^{6}$ Department of Software, Sungkyunkwan University, Seoul, South Korea. ${ }^{7}$ Centre for Health Protection, Hong Kong, Hong Kong, Special Administrative Region of China. ${ }^{8}$ MRC Centre for Outbreak Analysis and Modelling, Department for Infectious Disease Epidemiology, Imperial College London, London, UK.

Received: 21 July 2017 Accepted: 25 March 2018

Published online: 18 April 2018

\section{References}

1. WHO: Global priority list of antibiotic-resistant bacteria to guide research, discovery, and development of new antibiotics. 2017.

2. Hospital Authority HK. Fact Sheet on the Control of Methicillin-Resistant S. aureus (MRSA) in Hong Kong Hospitals In; 2006. p. 1.

3. Garazi M, Edwards B, Caccavale D, Auerbach C, Wolf-Klein G. Nursing homes as reservoirs of MRSA: myth or reality? J Am Med Dir Assoc. 2009;10(6):414-8.

4. Mody L, Kauffman CA, Donabedian S, Zervos M, Bradley SF. Epidemiology of Staphylococcus aureus colonization in nursing home residents. Clin Infect Dis. 2008;46(9):1368-73.

5. Reynolds C, Quan V, Kim D, Peterson E, Dunn J, Whealon M, Terpstra L,

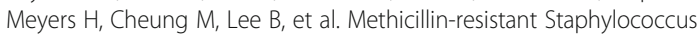
aureus (MRSA) carriage in 10 nursing homes in Orange County, California. Infect Control Hosp Epidemiol. 2011;32(1):91-3.

6. Gorwitz RJ, Kruszon-Moran D, McAllister SK, McQuillan G, McDougal LK, Fosheim GE, Jensen BJ, Killgore G, Tenover FC, Kuehnert MJ. Changes in the prevalence of nasal colonization with Staphylococcus aureus in the United States, 2001-2004. J Infect Dis. 2008;197(9):1226-34.

7. Cheng VC, Tai JW, Wong ZS, Chen JH, Pan KB, Hai Y, Ng WC, Chow DM, Yau MC, Chan JF, et al. Transmission of methicillin-resistant Staphylococcus aureus in the long term care facilities in Hong Kong. BMC Infect Dis. 2013;13:205.

8. David MZ, Mennella C, Mansour M, Boyle-Vavra S, Daum RS. Predominance of methicillin-resistant Staphylococcus aureus among pathogens causing skin and soft tissue infections in a large urban jail: risk factors and recurrence rates. J Clin Microbiol. 2008:46(10):3222-7.

9. Farley JE. Epidemiology, clinical manifestations, and treatment options for skin and soft tissue infection caused by community-acquired methicillinresistant Staphylococcus aureus. J Am Acad Nurse Pract. 2008;20(2):85-92.

10. Graham PL 3rd, Lin SX, Larson EL. A U.S. population-based survey of Staphylococcus aureus colonization. Ann Intern Med. 2006:144(5):318-25.

11. Felkner M, Rohde RE, Valle-Rivera AM, Baldwin T, Newsome LP. Methicillinresistant Staphylococcus aureus nasal carriage rate in Texas County jail inmates. J Correct Health Care. 2007;13:289-95.

12. Lee BY, McGlone SM, Song Y, Avery TR, Eubank S, Chang CC, Bailey RR, Wagener DK, Burke DS, Platt R, et al. Social network analysis of patient sharing among hospitals in Orange County, California. Am J Public Health. 2011;101(4):707-13.

13. Lee BY, Song Y, Bartsch SM, Kim DS, Singh A, Avery TR, Brown ST, Yilmaz SL, Wong KF, Potter MA, et al. Long-term care facilities: important participants of the acute care facility social network? PLoS One. 2011;6(12):e29342.

14. Jones A. The National Nursing Home Survey: 1999 summary. In: Vital and health statistics Series 13, Data from the National Health Survey, vol. 152; 2002. p. 1-116.

15. Patterson EJ, Preston SH. Estimating mean length of stay in prison: methods and applications. J Quant Criminol. 2008:24(1):33-49.

16. OECD. Average length of stay in hospitals. Health at a Glance 2017: OECD Indicators. 2017. ISBN: 9789264280403. https://doi.org/10.1787/health_ glance-2017-en

17. Bradley SF, Terpenning MS, Ramsey MA, Zarins LT, Jorgensen KA, Sottile WS, Schaberg DR, Kauffman CA. Methicillin-resistant Staphylococcus aureus: colonization and infection in a long-term care facility. Ann Intern Med. 1991; 115(6):417-22.

18. Sanford MD, Widmer AF, Bale MJ, Jones RN, Wenzel RP. Efficient detection and long-term persistence of the carriage of methicillin-resistant Staphylococcus aureus. Clin Infect Dis. 1994;19(6):1123-8.

19. Hethcote HW. The mathematics of infectious diseases. SIAM Rev. 2000; 42(4):599-653. 
20. Grundmann $\mathrm{H}$, Hellriegel B. Mathematical modelling: a tool for hospital infection control. Lancet Infect Dis. 2006;6(1):39-45.

21. van Kleef E, Robotham JV, Jit M, Deeny SR, Edmunds WJ. Modelling the transmission of healthcare associated infections: a systematic review. BMC Infect Dis. 2013;13:294.

22. Chamchod F, Ruan S. Modeling the spread of methicillin-resistant Staphylococcus aureus in nursing homes for elderly. PLoS One. 2012; 7(1):e29757.

23. Batina NG, Crnich CJ, Anderson DF, Dopfer D. Identifying conditions for elimination and epidemic potential of methicillin-resistant Staphylococcus aureus in nursing homes. Antimicrob Resist Infect Control. 2016;5:32.

24. Batina NG, Crnich CJ, Anderson DF, Dopfer D. Models to predict prevalence and transition dynamics of methicillin-resistant Staphylococcus aureus in community nursing homes. Am J Infect Control. 2016;44(5):507-14.

25. Kajita E, Okano JT, Bodine EN, Layne SP, Blower S. Modelling an outbreak of an emerging pathogen. Nat Rev Microbiol. 2007:5(9):700-9.

26. Beauparlant M, Smith R. A metapopulation model for the spread of MRSA in correctional facilities. Infect Dis Model. 2016;1(1):11-27.

27. Hartley DM, Furuno JP, Wright MO, Smith DL, Perencevich EN. The role of institutional epidemiologic weight in guiding infection surveillance and control in community and hospital populations. Infect Control Hosp Epidemiol. 2006;27(2):170-4.

28. Barnes SL, Harris AD, Golden BL, Wasil EA, Furuno JP. Contribution of interfacility patient movement to overall methicillin-resistant Staphylococcus aureus prevalence levels. Infect Control Hosp Epidemiol. 2011;32(11):1073-8.

29. Lee BY, Bartsch SM, Wong KF, Singh A, Avery TR, Kim DS, Brown ST, Murphy CR, Yilmaz SL, Potter MA, et al. The importance of nursing homes in the spread of methicillin-resistant Staphylococcus aureus (MRSA) among hospitals. Med Care. 2013;51(3):205-15.

30. Lee BY, Singh A, Bartsch SM, Wong KF, Kim DS, Avery TR, Brown ST, Murphy CR, Yilmaz SL, Huang SS. The potential regional impact of contact precaution use in nursing homes to control methicillin-resistant Staphylococcus aureus. Infect Control Hosp Epidemiol. 2013;34(2):151-60.

31. Lesosky M, McGeer A, Simor A, Green K, Low DE, Raboud J. Effect of patterns of transferring patients among healthcare institutions on rates of nosocomial methicillin-resistant Staphylococcus aureus transmission: a Monte Carlo simulation. Infect Control Hosp Epidemiol. 2011;32(2):136-47.

32. Harbarth S, Fankhauser C, Schrenzel J, Christenson J, Gervaz P, BandieraClerc C, Renzi G, Vernaz N, Sax H, Pittet D. Universal screening for methicillin-resistant Staphylococcus aureus at hospital admission and nosocomial infection in surgical patients. JAMA. 2008;299(10):1149-57.

33. Jeyaratnam D, Whitty CJ, Phillips K, Liu D, Orezzi C, Ajoku U, French GL. Impact of rapid screening tests on acquisition of meticillin resistant Staphylococcus aureus: cluster randomised crossover trial. BMJ. 2008; 336(7650):927-30.

34. Rioux C, Armand-Lefevre L, Guerinot W, Andremont A, Lucet JC. Acquisition of methicillin-resistant Staphylococcus aureus in the acute care setting: incidence and risk factors. Infect Control Hosp Epidemiol. 2007;28(6):733-6.

35. Rebmann T, Aureden K. Preventing methicillin-resistant Staphylococcus aureus transmission in hospitals: an executive summary of the Association for Professionals in infection control and epidemiology, Inc, elimination guide. Am J Infect Control. 2011;39(7):595-8.

36. Larson E. A causal link between handwashing and risk of infection? Examination of the evidence. Infect Control. 1988;9(1):28-36.

37. Ndawula EM, Brown L. Mattresses as reservoirs of epidemic methicillinresistant Staphylococcus aureus. Lancet. 1991;337(8739):488.

38. Perry C, Marshall R, Jones E. Bacterial contamination of uniforms. J Hospital Infect. 2001;48(3):238-41.

39. Boyce JM, Potter-Bynoe G, Chenevert C, King T. Environmental contamination due to methicillin-resistant Staphylococcus aureus: possible infection control implications. Infect Control Hosp Epidemiol. 1997;18(9):622-7.

40. Albrich WC, Harbarth S. Health-care workers: source, vector, or victim of MRSA? Lancet Infect Dis. 2008:8(5):289-301.

41. Dulon M, Peters C, Schablon A, Nienhaus A. MRSA carriage among healthcare workers in non-outbreak settings in Europe and the United States: a systematic review. BMC Infect Dis. 2014;14:363.

42. Harrison EM, Ludden C, Brodrick HJ, Blane B, Brennan G, Morris D, Coll F, Reuter S, Brown NM, Holmes MA, et al. Transmission of methicillin-resistant Staphylococcus aureus in long-term care facilities and their related healthcare networks. Genome Med. 2016;8(1):102.
43. Lee XJ, Fulford GR, Pettitt AN, Ruggeri F. A stochastic model for MRSA transmission within a hospital ward incorporating environmental contamination. Epidemiol Infect. 2017;145(4):825-38.

44. Lei H, Jones RM, Li Y. Exploring surface cleaning strategies in hospital to prevent contact transmission of methicillin-resistant Staphylococcus aureus. BMC Infect Dis. 2017;17(1):85.

45. Plipat N, Spicknall IH, Koopman JS, Eisenberg JN. The dynamics of methicillin-resistant Staphylococcus aureus exposure in a hospital model and the potential for environmental intervention. BMC Infect Dis. 2013; 13:595.

46. Wang $L$, Ruan S. Modeling nosocomial infections of methicillin-resistant Staphylococcus aureus with environment contamination. Sci Rep. 2017; 7(1):580.

47. Bhalla A, Pultz NJ, Gries DM, Ray AJ, Eckstein EC, Aron DC, Donskey CJ. Acquisition of nosocomial pathogens on hands after contact with environmental surfaces near hospitalized patients. Infect Control Hosp Epidemiol. 2004;25(2):164-7.

48. Dancer SJ. Controlling hospital-acquired infection: focus on the role of the environment and new technologies for decontamination. Clin Microbiol Rev. 2014;27(4):665-90.

49. Goodman ER, Platt R, Bass R, Onderdonk AB, Yokoe DS, Huang SS. Impact of an environmental cleaning intervention on the presence of methicillinresistant Staphylococcus aureus and vancomycin-resistant enterococci on surfaces in intensive care unit rooms. Infect Control Hosp Epidemiol. 2008; 29(7):593-9.

50. Wang J, Wang L, Magal P, Wang Y, Zhuo J, Lu X, Ruan S. Modelling the transmission dynamics of meticillin-resistant Staphylococcus aureus in Beijing Tongren hospital. J Hospital Infect. 2011;79(4):302-8.

51. David MZ, Daum RS. Community-associated methicillin-resistant Staphylococcus aureus: epidemiology and clinical consequences of an emerging epidemic. Clin Microbiol Rev. 2010;23(3):616-87.

52. Chamchod F, Ruan S. Modeling methicillin-resistant Staphylococcus aureus in hospitals: transmission dynamics, antibiotic usage and its history. Theor Biol Med Model. 2012;9:25.

53. Roghmann MC, Johnson JK, Sorkin JD, Langenberg P, Lydecker A, Sorace B, Levy L, Mody L. Transmission of methicillin-resistant Staphylococcus aureus (MRSA) to healthcare worker gowns and gloves during Care of Nursing Home Residents. Infect Control Hosp Epidemiol. 2015;36(9):1050-7.

54. Shiomori T, Miyamoto H, Makishima K, Yoshida M, Fujiyoshi T, Udaka T, Inaba T, Hiraki N. Evaluation of bedmaking-related airborne and surface methicillin-resistant Staphylococcus aureus contamination. J Hospital Infect. 2002;50(1):30-5.

55. Sherertz RJ, Reagan DR, Hampton KD, Robertson KL, Streed SA, Hoen HM, Thomas R, Gwaltney JM Jr. A cloud adult: the Staphylococcus aureus-virus interaction revisited. Ann Intern Med. 1996;124(6):539-47.

56. Wong JG, Chen MI, Win MK, Ng PY, Chow A. Length of stay an important mediator of hospital-acquired methicillin-resistant Staphylococcus aureus. Epidemiol Infect. 2016;144(6):1248-56.

57. Lowy FD, Aiello AE, Bhat M, Johnson-Lawrence VD, Lee MH, Burrell E, Wright LN, Vasquez G, Larson EL. Staphylococcus aureus colonization and infection in New York state prisons. J Infect Dis. 2007;196(6):911-8.

58. Wang X, Panchanathan S, Chowell G. A data-driven mathematical model of CA-MRSA transmission among age groups: evaluating the effect of control interventions. PLoS Comput Biol. 2013;9(11):e1003328.

59. Montgomery CP, Boyle-Vavra S, Adem PV, Lee JC, Husain AN, Clasen J, Daum RS. Comparison of virulence in community-associated methicillinresistant Staphylococcus aureus pulsotypes USA300 and USA400 in a rat model of pneumonia. J Infect Dis. 2008;198(4):561-70.

60. Li M, Diep BA, Villaruz AE, Braughton KR, Jiang X, DeLeo FR, Chambers HF, Lu Y, Otto M. Evolution of virulence in epidemic community-associated methicillin-resistant Staphylococcus aureus. Proc Natl Acad Sci U S A. 2009; 106(14):5883-8

61. Lina G, Boutite F, Tristan A, Bes M, Etienne J, Vandenesch F. Bacterial competition for human nasal cavity colonization: role of staphylococcal agr alleles. Appl Environ Microbiol. 2003;69(1):18-23.

62. Mossong J, Hens N, Jit M, Beutels P, Auranen K, Mikolajczyk R, Massari M, Salmaso S, Tomba GS, Wallinga J, et al. Social contacts and mixing patterns relevant to the spread of infectious diseases. PLoS Med. 2008;5(3):e74.

63. Kwok KO, Cowling BJ, Wei WW, Wu KM, Read JM, Lessler J, Cummings DA, Peiris JS, Riley S. Social contacts and the locations in which they occur as risk factors for influenza infection. Proc Biol Sci. 2014;281(1789):20140709. 
64. Polgreen PM, Tassier TL, Pemmaraju SV, Segre AM. Prioritizing healthcare worker vaccinations on the basis of social network analysis. Infect Control Hosp Epidemiol. 2010;31(9):893-900.

65. Vanhems $P$, Barrat A, Cattuto C, Pinton JF, Khanafer N, Regis C, Kim BA, Comte B, Voirin N. Estimating potential infection transmission routes in hospital wards using wearable proximity sensors. PLoS One. 2013;8(9):e73970.

66. Dulon M, Haamann F, Peters C, Schablon A, Nienhaus A. MRSA prevalence in European healthcare settings: a review. BMC Infect Dis. 2011;11:138.

67. Zhang J, Gu FF, Zhao SY, Xiao SZ, Wang YC, Guo XK, Ni YX, Han LZ. Prevalence and molecular epidemiology of Staphylococcus aureus among residents of seven nursing homes in shanghai. PLoS One. 2015; 10(9):e0137593.

68. Robicsek A, Beaumont JL, Paule SM, Hacek DM, Thomson RB Jr, Kaul KL, King P, Peterson LR. Universal surveillance for methicillin-resistant Staphylococcus aureus in 3 affiliated hospitals. Ann Intern Med. 2008; 148(6):409-18.

69. Cooper BS, Stone SP, Kibbler CC, Cookson BD, Roberts JA, Medley GF, Duckworth G, Lai R, Ebrahim S. Isolation measures in the hospital management of methicillin resistant Staphylococcus aureus (MRSA): systematic review of the literature. BMJ. 2004;329(7465):533.

70. Chang S, Sethi AK, Eckstein BC, Stiefel U, Cadnum JL, Donskey CJ. Skin and environmental contamination with methicillin-resistant Staphylococcus aureus among carriers identified clinically versus through active surveillance. Clin Infect Dis. 2009;48(10):1423-8.

71. Donker T, Wallinga J, Grundmann H. Patient referral patterns and the spread of hospital-acquired infections through national health care networks. PLoS Comput Biol. 2010;6(3):e1000715.

72. Mody L. Infection control issues in older adults. Clin Geriatr Med. 2007;23(3): 499-514. vi

73. Harbarth S. Control of endemic methicillin-resistant Staphylococcus aureus-recent advances and future challenges. Clin Microbiol Infect. 2006;12(12):1154-62

74. Lawes T, Lopez-Lozano JM, Nebot CA, Macartney G, Subbarao-Sharma R, Dare CR, Wares KD, Gould IM. Effects of national antibiotic stewardship and infection control strategies on hospital-associated and communityassociated meticillin-resistant Staphylococcus aureus infections across a region of Scotland: a non-linear time-series study. Lancet Infect Dis. 2015; 15(12):1438-49.

75. WHO. World report on ageing and health. 2015. ISBN: 9789241565042. http://apps.who.int/iris/bitstream/handle/10665/186463/9789240694811 eng.pdf?sequence $=1$.

76. Ho PL, Chiu SS, Chan MY, Gan Y, Chow KH, Lai EL, Lau YL. Molecular epidemiology and nasal carriage of Staphylococcus aureus and methicillinresistant S. Aureus among young children attending day care centers and kindergartens in Hong Kong. J Infect. 2012;64(5):500-6.

77. Rahmandad HaS J. Heterogeneity and network structure in the dynamics of diffusion: comparing agent-based and differential equation models. Manag Sci. 2008;54(5):998-1014.

78. Figueredo GP, Siebers PO, Owen MR, Reps J, Aickelin U. Comparing stochastic differential equations and agent-based modelling and simulation for early-stage cancer. PLoS One. 2014;9(4):e95150.

\section{Submit your next manuscript to BioMed Central and we will help you at every step:}

- We accept pre-submission inquiries

- Our selector tool helps you to find the most relevant journal

- We provide round the clock customer support

- Convenient online submission

- Thorough peer review

- Inclusion in PubMed and all major indexing services

- Maximum visibility for your research

Submit your manuscript at www.biomedcentral.com/submit

Biomed Central 